\title{
Percutaneous Atrial Septal Defect Closure in Adult Ebstein's Anomaly with Exertional Hypoxemia
}

\author{
Kensuke Oka, ${ }^{1}$ MD, Mitsuru Seki,${ }^{1}$ MD, Koichi Kataoka, ${ }^{1}$ MD, Tomoyuki Sato, ${ }^{1}$ MD, \\ Yasushi Imai, ${ }^{2} \mathrm{MD}$ and Takanori Yamagata, ${ }^{1} \mathrm{MD}$
}

\begin{abstract}
Summary
In Ebstein's anomaly, percutaneous atrial septal defect (ASD) closure for the treatment of hypoxemia due to a right-to-left interatrial shunt remains controversial. We report the case of a 40-year-old woman with Ebstein's anomaly who developed cyanosis and shortness of breath on exercise. Her symptoms improved after percutaneous ASD closure and her clinical course has been good during follow-up. The balloon ASD occlusion test, combined with dobutamine stimulation before the procedure, is useful to confirm treatment indication. A prior electrophysiological evaluation is also important because Ebstein's anomaly is often complicated by atrioventricular recurrent tachycardia.
\end{abstract}

(Int Heart J 2020; 61: 620-623)

Key words: ASD occlusion test, Dobutamine stimulation, Electrophysiological study, Interatrial shunt, Cyanosis

$\mathrm{E}$ bstein's anomaly was first reported in 1866 by Wilhelm Ebstein. ${ }^{1)}$ This relatively rare heart abnormality accounts for $0.5 \%$ of all congenital heart disease. ${ }^{2)}$ Clinical symptoms depend on the disease severity mainly defined by tricuspid valve and right ventricular (RV) function. Even in patients who required no therapeutic intervention during childhood, as tricuspid valve incompetence and RV compliance deteriorate, cyanosis due to a right-to-left shunt via the ASD may manifest in adulthood. Currently, there is no established therapeutic strategy for these patients. Although percutaneous ASD closure is one of the treatment options available to improve hypoxemia, this may lead to elevation of central venous pressure (CVP) or low cardiac output following decrease of preload to the left ventricle. Therefore, the usefulness of percutaneous ASD closure for Ebstein's anomaly is under discussion and optimal patient selection is important. Here, we report the case of a 40-year-old woman with Ebstein's anomaly whose symptoms improved after percutaneous ASD closure. In this case report, we mention the importance of careful patient selection using a balloon ASD occlusion test in combination with dobutamine stimulation and the evaluation of arrhythmia prior to percutaneous ASD closure.

\section{Case Report}

A 40-year-old woman was diagnosed with Ebstein's anomaly at the age of 2 and had been followed-up without intervention from childhood. The patient gave birth to her first healthy baby at the age of 28 years, with no worsening of heart failure. She developed hypoxemia on exertion at the age of 32, during her second pregnancy; however, the cause could not be identified at this point. At 40 years of age, further examination by contrast-enhanced computed tomography revealed an ostium secundum ASD (Figure 1A), which had not been detected by transthoracic echocardiography. The patient suffered from shortness of breath during exertion, and fatigability, which was defined as New York Heart Association (NYHA) functional class II. A cardiopulmonary exercise test showed desaturation after exercise from $98 \%$ to $79 \%$ of percutaneous oxygen saturation $\left(\mathrm{SpO}_{2}\right)$, suggesting that a right-to-left interatrial shunt was the cause.

At 40 years of age, the patient was admitted for evaluating the indication for percutaneous ASD closure. Cardiac examination revealed no fixed splitting of the second heart sound, a Levine I/IV systolic regurgitant heart murmur, no diastolic heart murmur, a blood pressure of $108 / 60 \mathrm{mmHg}$, and a heart rate of 80 beats/minute. Routine blood tests showed no anemia (hemoglobin $14.1 \mathrm{~g} /$ $\mathrm{dL}$ ), normal kidney and liver function, brain natriuretic peptide of $56.5 \mathrm{pg} / \mathrm{mL}$ (reference range $<18.4 \mathrm{pg} / \mathrm{mL}$ ), and human atrial natriuretic peptide of $106 \mathrm{pg} / \mathrm{mL}$ (reference range $<43 \mathrm{pg} / \mathrm{mL}$ ). A chest X-ray revealed a cardiothoracic ratio of 0.54 . Electrocardiography showed sinus rhythm with strikingly tall and peaked $\mathrm{P}$ waves and no delta wave (Figure 1B). Transthoracic echocardiography revealed a left ventricular ejection fraction of $80 \%$ and left ventricular end-diastolic diameter of $34 \mathrm{~mm}$ (78\% of

From the ${ }^{1}$ Department of Pediatrics, Jichi Medical University, Tochigi, Japan and ${ }^{2}$ Department of Cardiovascular Medicine, Jichi Medical University, Tochigi, Japan.

Address for correspondence: Mitsuru Seki, MD, Department of Pediatrics, Jichi Medical University, 3311-1, Yakushiji, Shimotsuke, Tochigi, 329-0498, Japan. E-mail: m-seki@jichi.ac.jp

Received for publication November 26, 2019. Revised and accepted January 13, 2020

Released in advance online on J-STAGE May 15, 2020.

doi: 10.1536/ihj.19-641

All rights reserved by the International Heart Journal Association. 

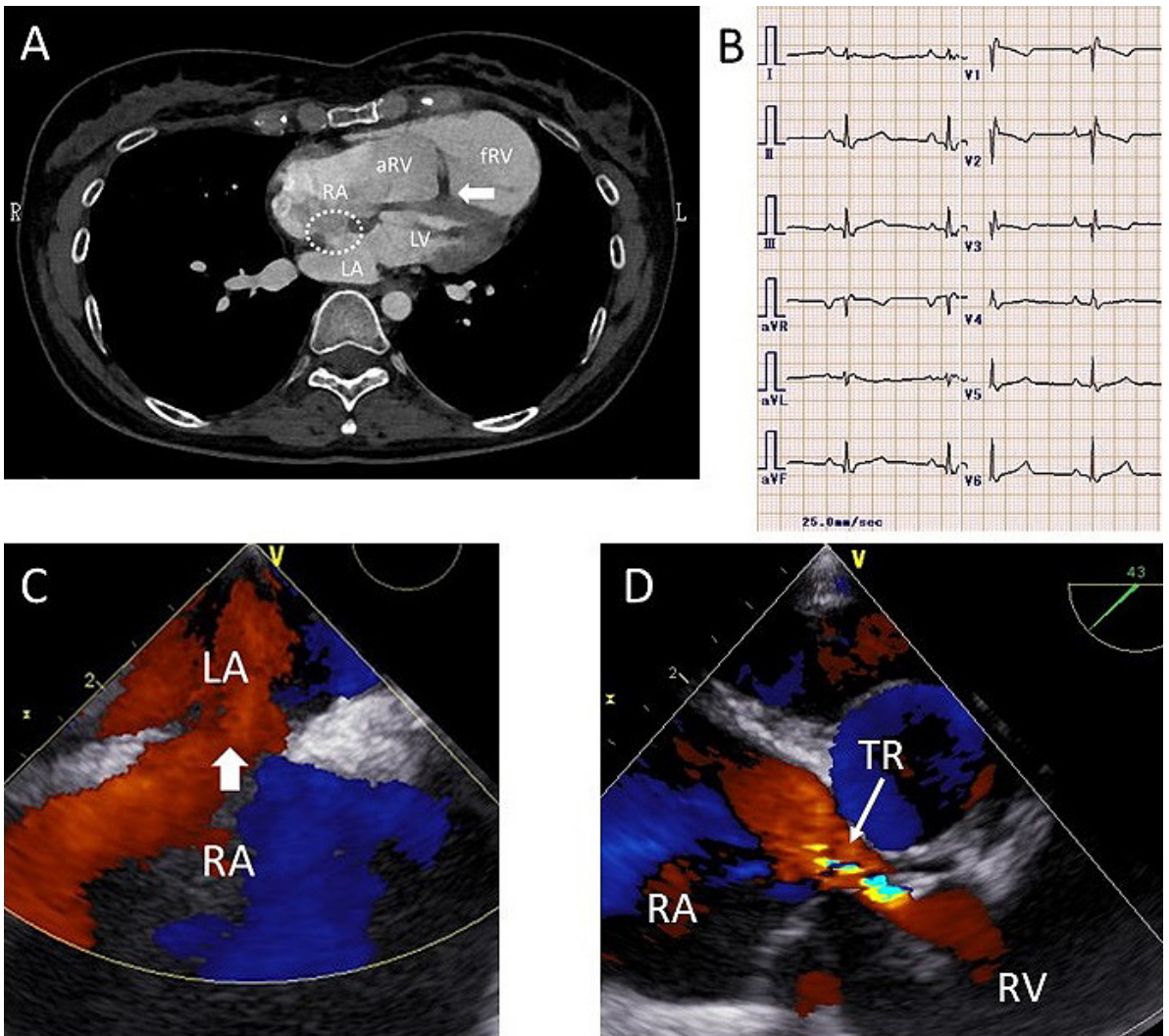

Figure 1. A: Thoracic contrast-enhanced computed tomography. The arrow in the figure shows the attachment site of the tricuspid valve septal leaflet, which is displaced toward the apex. The circle shows an ASD (17 mm in diameter). B: Electrocardiogram. Sinus rhythm, HR 68/minute, strikingly tall and peaked P wave, incomplete right bundle branch block, $\mathrm{Q}$ waves in lead $\mathrm{V}_{1-3}$, and no delta wave. C: Transesophageal echocardiography. Shunt from right atrium to left atrium. The arrow shows an ASD. D: Transesophageal echocardiography showed mild tricuspid regurgitation (the arrow). ASD indicates atrial septal defect; RA, right atrium; LA, left atrium; aRV, atrialized right ventricle; fRV, functional right ventricle; LV, left ventricle.

normal value). Tricuspid septal leaflet annular attachment showed a displacement of $22 \mathrm{~mm}$ toward the apex with mild tricuspid valve regurgitation (TR) (TR pressure gradient of $15 \mathrm{mmHg}$ )

The Table shows a summary of cardiac catheterization findings. At rest, the patient showed an $\mathrm{SaO}_{2}$ of $93 \%$, a ratio of pulmonary to systemic blood flow (Qp/Qs) of 0.9 , pulmonary artery pressure of $24 / 8$ (14) $\mathrm{mmHg}$, and central venous pressure (CVP) $7 \mathrm{mmHg}$. Her functional $\mathrm{RV}$ end-diastolic volume and RV ejection fraction calculated by biplane cineangiography were $80.8 \mathrm{~mL}$ (70\% of normal value) and $55.4 \%$, respectively. Transesophageal echocardiography (TEE) showed an ostium secundum ASD (13.3 $\mathrm{mm}$ in diameter), a circumferentially large enough atrial rim, bidirectional interatrial shunting via the ASD (Figure 1C), and mild TR (Figure 1D). During an ASD balloon occlusion test using a 24-mm diameter AMPLATZER $^{\mathrm{TM}}$ Sizing Balloon (St. Jude Medical, St. Paul, MN, USA) (Figure 2A), $\mathrm{SpO}_{2}$ increased from 93\% to $97 \%$ with no hemodynamic changes, i.e., no elevation of CVP or decrease of systemic blood pressure. To assess the impact of exercise stress, catecholamine stimulation by dobutamine infusion $(5-15 \mu \mathrm{g} / \mathrm{kg} /$ minute) was performed. We monitored systemic arterial pressure, $\mathrm{CVP}, \mathrm{SpO}_{2}$, and right ventricular cardiac output calculated by TEE during dobutamine stimulation over 40 minutes, revealing an increase of CVP from 7 to $8 \mathrm{mmHg}$ and no exacerbation of TR according to TEE. RV cardiac output increased from 3.7 to $6.7 \mathrm{~L} /$ minute, suggesting that systemic cardiac output also increased to the same extent. Although we decided that the ASD could be closed, an electrophysiological study (EPS) revealed atrioventricular recurrent tachycardia (AVRT) with the right Kent bundle in the circuit. AVRT was easily induced by atrial extrastimuli (Figure 2 B). Therefore, catheter ablation of the accessory pathway in the tricuspid annulus was performed two months later. The patient was followed-up for seven months without recurrence of tachycardia.

Percutaneous ASD closure was then performed. The ASD occlusion test was repeated, with the same findings. Balloon sizing of the ASD was $15.9 \mathrm{~mm}$, and the patient underwent successful percutaneous ASD closure with a 17-mm diameter AMPLATZER ${ }^{\mathrm{TM}}$ Septal Occluder (St. Jude Medical, St. Paul, MN, USA). She was discharged without complications. After the procedure, her subjective symptoms improved from NYHA functional class II to I. Her clinical course has been uneventful, with no exacerbation of heart failure during three years' follow-up. 
Table. Summary of Hemodynamics of Cardiac Catheterization

\begin{tabular}{cc|ccccc}
\hline $\begin{array}{c}\text { Balloon } \\
\text { occlusion }\end{array}$ & $\begin{array}{c}\text { Dobutamine } \\
(\mu \mathrm{g} / \mathrm{kg} / \mathrm{minute})\end{array}$ & $\begin{array}{c}\mathrm{HR} \\
(/ \mathrm{minute})\end{array}$ & $\begin{array}{c}\mathrm{AoP} \\
(\mathrm{mmHg})\end{array}$ & $\begin{array}{c}\mathrm{CVP} \\
(\mathrm{mmHg})\end{array}$ & $\begin{array}{c}\mathrm{RVCO} \\
(\mathrm{L} / \text { minute })\end{array}$ & $\mathrm{SpO}_{2}(\%)$ \\
\hline- & - & 64 & $83 / 51$ & 7 & 3.7 & 93 \\
+ & - & 65 & $105 / 53$ & 7 & 4.2 & 97 \\
+ & 5 & 63 & $98 / 51$ & 7 & 3.9 & 97 \\
+ & 10 & 96 & $137 / 56$ & 8 & 6.2 & 97 \\
+ & 15 & 124 & $128 / 54$ & 8 & 6.7 & 97 \\
- & 15 & 127 & $138 / 58$ & 8 & - & 93 \\
\hline
\end{tabular}

ASD balloon occlusion and the dobutamine stimulation test were performed to confirm the treatment indication for ASD closure. After ASD balloon occlusion, $\mathrm{SpO}_{2}$ increased from $93 \%$ to $97 \%$, with no elevation of CVP or fall in systemic blood pressure. Dobutamine infusion revealed a slight increase of CVP, from 7 to $8 \mathrm{mmHg}$. ASD indicates atrial septal defect; $\mathrm{SpO}_{2}$, percutaneous oxygen saturation; CVP, central venous pressure; HR, heart rate; AoP, aortic blood pressure; RVEDP, right ventricular end-diastolic pressure; and RVCO, right ventricular cardiac output.

A

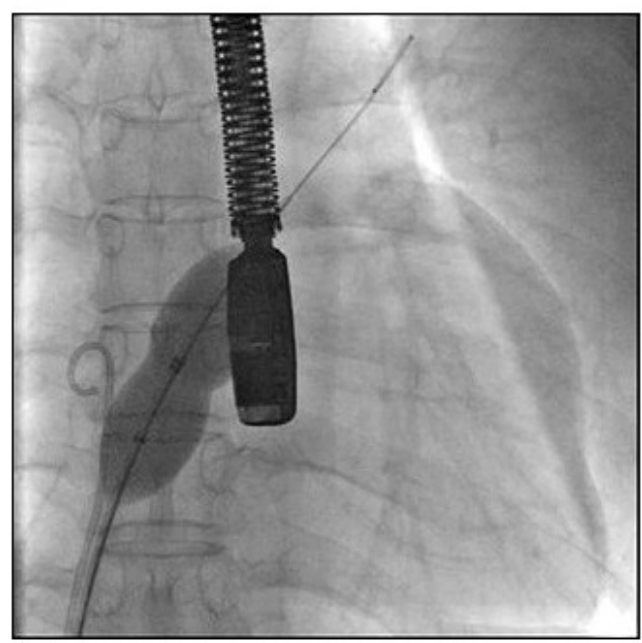

B

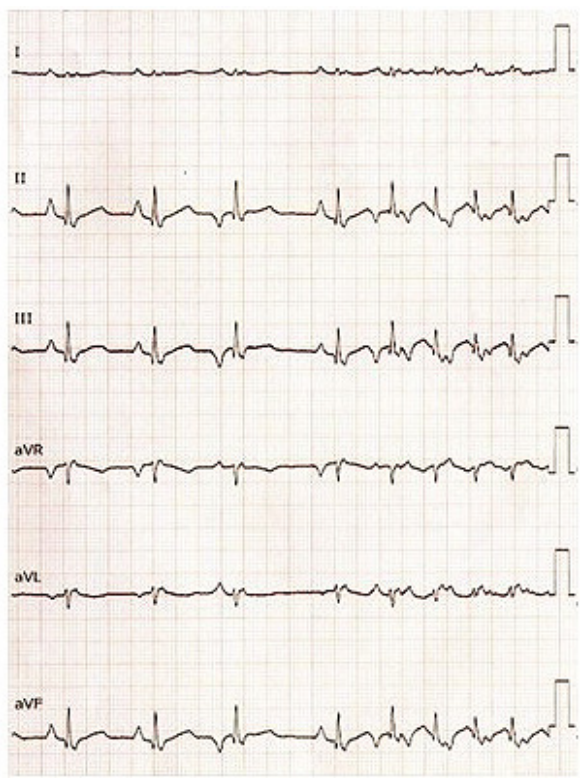

Figure 2. A: Balloon occlusion test of atrial septal defect using a 24-mm diameter AMPLATZER ${ }^{\mathrm{TM}}$ Sizing Balloon. B: Electrocardiogram during electrophysiological study. Atrioventricular recurrent tachycardia was easily induced by atrial extrastimuli.

\section{Discussion}

To date, there is no definitive guideline for the treatment of adult patients with Ebstein's anomaly who have progressive heart failure and hypoxia due to a right-to-left interatrial shunt. Surgical valvuloplasty or replacement of the tricuspid valve with ASD closure are considered to be the standard treatment for these patients. Percutaneous ASD closure for treatment of desaturation in Ebstein's anomaly is controversial. Extensive examination of hemodynamics by ASD test occlusion, combined with dobutamine stimulation and electrophysiological evaluation, are important to confirm the indication for ASD closure. Accurate assessment of the severity of TR is required to assess whether surgical intervention should be performed to improve right heart function. We evaluated this patient in accordance with this strategy, and treatment was successful with a good subsequent clinical course.
It has been reported that NYHA functional class $\geq$ III or a cardiothoracic ratio of $>0.6$ on chest X-ray increase perioperative mortality, suggesting that early surgical repair may improve long-term outcome. ${ }^{3)}$ If right ventricular dysfunction is too severe to perform biventricular repair, 1.5 ventricular repair or a Fontan procedure may be performed even in adult patients. ${ }^{4)}$ However, as in the present case, careful consideration is required to decide on a treatment strategy in patients with hypoxemia due to a rightto-left interatrial shunt and mild to moderate TR because clinical symptoms may improve without surgical intervention for the tricuspid valve. In addition to the degree of $\mathrm{TR}$, functional RV volume is also important. In the present case, although we evaluated functional RV volume and ejection fraction by the measurement of biplane cineangiography, more detailed examination, such as cardiac magnetic resonance imaging, might be useful for assessing RV function. 
In the atypical or complicated cases, careful and accurate hemodynamic assessment is important to determine the appropriate treatment indication.5) There are few reports of percutaneous ASD closure for adult patients with Ebstein's anomaly who have right-to-left interatrial shunts. ASD closure may result in the exacerbation of TR by increasing right ventricular volume overload. Low cardiac output may occur because of the decrease in blood flow to the left side of the heart through the interatrial shunt. Belli, et al. advised that ASD closure could not improve long-term prognosis even if patients felt a symptomatic improvement because the existence of a right-to-left shunt reflected poor right ventricular compliance. $\left.{ }^{6}\right)$ However, Jategaonkar, et al. performed percutaneous ASD closure in nine cases of adult Ebstein's anomaly, of which four had right-to-left shunts; postoperative $\mathrm{SpO}_{2}$ and NYHA functional class improved in all cases. ${ }^{7}$ Atiq, et al. also reported percutaneous ASD closure for 17 cases of right ventricular hypoplasia in children, including six cases of Ebstein's anomaly. ${ }^{8)}$ They recommend ASD balloon test occlusion for 15 minutes to confirm the indication for percutaneous ASD closure, and performed ASD closure if the test occlusion revealed no significant drop in systemic pressures $(>10 \%)$ or rise in right atrial pressure $(>20 \%)$. Jategaonkar, et al. also mention that test occlusion for a considerable time (i.e., 1-2 hours) is appropriate, and advise that it is useful to combine the ASD occlusion test with dobutamine stimulation to simulate exercise conditions. ${ }^{7)}$ Even though there are no hemodynamic changes on ASD occlusion, significant elevation of CVP after dobutamine infusion suggests that there is no treatment indication for ASD closure. However, it should be noted that catecholamine stimulation cannot completely predict hemodynamic changes during exercise.

Approximately $25 \%$ of Ebstein's anomaly cases have associated Wolff-Parkinson-White (WPW) syndrome.9) The acute success rate of ablation for atrioventricular reciprocating tachycardia is lower in patients with Ebstein's anomaly than patients with normal cardiac anatomy. In addition, these patients are more likely to have recurrence. ${ }^{10)}$ In the case of the left accessory pathway, the trans-ASD approach is unavailable after ASD closure. Even in the case of the right accessory pathway, as in the present case, an increase of right heart volume overload may induce frequent AVRT after ASD closure. Therefore, prior to ASD closure, EPS and catheter ablation should be performed to treat arrhythmia. ${ }^{11}$

\section{Conclusions}

Percutaneous ASD closure for Ebstein's anomaly patients with exertional hypoxemia may improve exercise tolerance by eliminating the right-to-left shunt. However, to avoid exacerbation of right heart failure and low cardiac output, careful preoperative assessment of treatment indication should include the degree of TR and right ventricular function. To predict hemodynamic changes after ASD closure, ASD occlusion with dobutamine stimulation are useful. To reduce or eliminate the likelihood of arrhythmias, especially in WPW syndrome, it is important to perform EPS and catheter ablation before ASD closure. Since long-term prognosis after percutaneous ASD closure remains unclear, further follow-up and investigation in a larger series of patients is required.

\section{Disclosure}

Conflicts of interest: None.

\section{References}

1. Schiebler GL, Gravenstein JS, Van Mierop LH. Ebstein's anomaly of the tricuspid valve. Translation of original description with comments. Am J Cardiol 1968; 22: 867-73.

2. Dearani JA, Danielson GK. Congenital Heart Surgery Nomenclature and Database Project: Ebstein's anomaly and tricuspid valve disease. Ann Thorac Surg 2000; 69: s106-17.

3. Badiu CC, Schereiber C, Hörer J, et al. Early timing of surgical intervention in patients with Ebstein's anomaly predicts superior long-term outcome. Eur J Cardiothorac Surg 2010; 37: 186-92.

4. Takagaki M, Ishino K, Kawada M, et al. Total right ventricular exclusion improves left ventricular function in patients with end-stage congestive right ventricular failure. Circulation 2003; 108: II-226-9.

5. Konagai N, Fukui S, Kitano M, et al. Successful transcatheter atrial septal defect closure prior to coronary artery bypass grafting using anti-congestive therapies and intraaortic balloon pumping in a patient with severe ischemic cardiomyopathy and triple-vessel coronary artery disease. Int Heart J 2018; 59: 14804.

6. Belli E, Rabot M, Petit J, Gouton M. Ebstein's anomaly in adults: Modified cone reconstruction of the tricuspid valve is associated with promising outcomes. Arch Cardiovasc Dis 2017; 110: $325-33$

7. Jategaonkar SR, Scholtz W, Horstkotte D, Kececioglu D, Haas NA. Interventional Closure of Atrial Septal Defects in Adult Patients with Ebstein's Anomaly. Congenit Heart Dis 2011; 6: 374-81.

8. Atiq M, Lai L, Lee KJ, Benson LN. Transcatheter closure of atrial septal defects in children with a hypoplastic right ventricle. Catheter Cardiovas Interv 2005; 64: 112-6.

9. Kumar AE, Fyler DC, Miettinen OS, Nadas AS. Ebstein's anomaly. Clinical profile and natural history. Am J Cardiol 1971; 28: 84

10. Chetaille P, Walsh EP, Triedman JK. Outcomes of radiofrequency catheter ablation of atrioventricular reciprocating tachycardia in patients with congenital heart disease. Heart Rhythm 2004; 1: 168-73.

11. Hebe J. Ebstein's anomaly in adults. Arrhythmias: diagnosis and therapeutic approach. Thorac Cardiovasc Surg 2000; 48: 214-9. 